\title{
Evaluation of predictions of volatile fatty acid production rates by the Molly cow model
}

\author{
S. Ghimire, ${ }^{*}$ P. Gregorini, $\dagger$ and M. D. Hanigan* ${ }^{* 1}$ \\ *Virginia Polytechnic Institute and State University, Blacksburg 24061 \\ †DairyNZ Ltd., Private Bag 3221, Hamilton 3240, New Zealand
}

\begin{abstract}
Predicting ruminal volatile fatty acid (VFA) production is important, as VFA are an energy source to the animal, affect nutrient partitioning, and dictate methane production. The VFA production submodel in the Molly cow model was evaluated using data from 8 publications that reported VFA production rates for cattle. Evaluations were conducted with ruminal water balance predictions enabled and the ruminal VFA stoichiometry coefficients set to "mixed" for all diets, or "mixed" when forage represented between 20 and $80 \%$ of the diet, "concentrate" when $<20 \%$ forage, or "forage" when $>80 \%$ forage. Prediction errors were relatively insensitive to changes in VFA coefficients by diet type. Root mean square prediction errors (RMSPE) were 63,63 , and $49 \%$ for acetate, propionate, and butyrate production rates, respectively. A large proportion of the error was slope bias for acetate and butyrate, and a modest proportion for propionate. Because interconversions between acetate and propionate represent approximately $15 \%$ of the variation in net production rates, lack of such consideration in the model may contribute to the substantial model prediction errors. The potential of using thermodynamic equations to predict interconversions was assessed using observed ruminal $\mathrm{pH}$ and VFA concentrations from 2 studies and assuming constant hydrogen pressure and concentrations of $\mathrm{CO}_{2}, \mathrm{H}_{2} \mathrm{O}$, adenosine diphosphate, ATP, and inorganic P. Rate constants for conversion of acetate to propionate and propionate to acetate were derived independently from the control treatments and used to predict the fluxes for the other treatment. The observed changes in VFA concentrations and $\mathrm{pH}$ explained the observed changes in conversion of acetate to propionate, but overpredicted the change in the propionate to acetate flux in one study. When applied to the other study, the equations predicted the increase in propionate to acetate flux, but failed to predict the
\end{abstract}

Received September 25, 2012.

Accepted October 8, 2013.

${ }^{1}$ Corresponding author: mhanigan@vt.edu observed reduction in acetate to propionate flux. The inability to predict responses accurately may be due to a lack of data for controlling factors other than $\mathrm{pH}$ and VFA concentrations.

Key words: volatile fatty acids, Molly, thermodynamics

\section{INTRODUCTION}

Volatile fatty acids are products of enteric microbial fermentation that contribute about $72 \%$ of the energy required by the cow (Bergman, 1990). Volatile fatty acid production rates also affect nutrient partitioning (Moloney, 1998), and determine ruminal hydrogen supply, which is used for methane production (Elliot and Loosli, 1959). Pyruvate conversion to propionate consumes electrons, thereby reducing hydrogen supply (Janssen, 2010) and formation of acetate and butyrate release hydrogen (Kohn and Boston, 2000). Thus, ruminal fermentation patterns are linked to methanogenesis. Although some diversity exists in the metabolic pathways used to metabolize fermentable substrate among microbial species, the overall stoichiometry of VFA production is assumed to remain constant (Rodríguez et al., 2006). Thus, if VFA production can be understood and predicted, it will be possible to understand and predict hydrogen supply. Measurements of hydrogen production in vivo are difficult and inaccurate; thus, mechanistic representations of rumen metabolism can help to understand and assess manipulations of rumen fermentation for reducing hydrogen generation and, thereby, methane production (McAllister and Newbold, 2008).

Initial efforts to develop predictive models of individual VFA, such as the research work of Murphy et al. (1982), described a set of stoichiometry constants for conversion of each rumen fermented nutrient (starch, nonstarch soluble carbohydrate, hemicellulose, cellulose, and protein) to microbial biomass, acetate, propionate, butyrate, valerate, isovalerate, and isobutyrate (net yields) based on the model of Koong et al. (1975). The original model was devised to relate observed microbial growth and VFA production data to known inputs of rumen-available nutrients. The challenge that Murphy et al. (1982) encountered was the lack of measured 
rates of VFA production. To circumvent the problem, a value for the fraction of fermented substrate converted to microbial biomass was assumed and observed ruminal VFA molar concentrations were assumed equivalent to the molar proportions of synthesized VFA. Also, lack of data on minor VFA forced a reduction of the model to acetate, propionate, butyrate, and valerate. The derived stoichiometric coefficients for conversion of each nutrient to these 4 VFA were found to be different between high-concentrate and high-forage diets; thus, a set of coefficients was derived separately for each diet type. Argyle and Baldwin (1988) subsequently adopted these coefficients for use in the Molly cow model and used the average of the forage and concentrate coefficients to create a mixed class, yielding 3 discrete sets of coefficients.

Models based on these stoichiometric coefficients have been evaluated for accuracy and precision in predicting ruminal VFA concentrations (Bannink et al., 1997; Hanigan et al., 2006; Morvay et al., 2011), but little work has been undertaken to evaluate predictions of production rates and absorption rates of individual VFA. Therefore, it is unclear whether the observed bias in predicting VFA concentrations relates to problems in predicting VFA absorption or VFA production. Bannink et al. (1997) explored various hypotheses for the observed prediction errors and also concluded that the cause was either associated with predictions of production or absorption.

Although, based only on concentration data, one cannot rule out the possibility that all of the problems are caused solely by absorption. Bannink et al. (1997) was unable to completely resolve the problem through changes in the representation of absorption. Improvements were realized with acetate, but no progress was made for propionate, butyrate, or valerate predictions. Thus, current evidence suggests that absorption predictions are not the primary cause of the prediction errors, although they may be contributing, thereby leaving production predictions as the primary hypothesis.

The stoichiometry constants of Murphy et al. (1982) are based on the implicit assumption that substrate supply is the primary determinant of production rate (i.e., the reaction series is essentially irreversible) or that reversibility is constant across diets and endproduct concentrations do not affect net flux rate. However, all the studies that use a fully interchanging model and more than $1 \mathrm{VFA}$ isotope have reported significant interconversion between VFA, which will affect the net amount of individual VFA produced and absorbed by the host animal. For example, Sutton et al. (2003) reported that VFA interconversions represented 14 to $17 \%$ of acetate net production, 13 to $18 \%$ of propionate net production, and 58 to $68 \%$ of butyrate net production. When comparing propionate to acetate conversions for the low-forage diet in their study, a condition that resulted in increased propionate production and propionate concentrations, the conversion increased by $50 \%$. Similarly, when Seal and Parker (1994) infused propionate into the rumen, the propionate to acetate conversion increased by $50 \%$ and the acetate-to-propionate conversion decreased by $50 \%$, resulting in a fairly substantial shift in net synthesis of each. Failure to consider these variable interconversion rates contributes error to current predictions of net VFA production rates.

Although zero time in vitro, perturbation of the steady state, and portal arterial difference methods have been used to estimate net production rates of VFA, they all have drawbacks. Most importantly, they all lack the ability to measure de novo synthesis rates and interconversions. Thus, the tracer method is currently the only method of estimating de novo VFA production rates in the rumen (France and Dijkstra, 2005). Tracer-based methods are implemented with the use of radioactive or stable isotopes with similar results. Although hydrogen-labeled VFA have been used, their reliability is much lower than carbon-labeled VFA (Leng and Leonard, 1965). Two approaches are used when using isotope dilution techniques: using only 1 labeled VFA and estimating combined fluxes of other VFA, or using individually labeled VFA. However, a single VFA isotope is not generally used because of the variable interconversion between VFA and lack of clearly defined rates of absorption (Hegarty and Nolan, 2007). Therefore, the isotope dilution technique provides the most complete assessment of VFA production and clearance from the rumen.

Because the conversion of pyruvate to acetate, propionate, or butyrate shares common intermediates and all of the reactions have negative free energy, the flow of carbon between these VFA can be explained by thermodynamic control (Ungerfeld and Kohn, 2006). Thus, we hypothesized that the cause of bias in predictions of VFA concentrations in the Molly cow model was inappropriate predictions of VFA production rates. The main objective of the current work was to evaluate predictions of VFA production rates by the Molly cow model using bovine data assembled from studies reported in the literature to determine accuracy and precision. Second, this work evaluated the potential of using thermodynamic equations to predict VFA interconversions.

\section{MATERIALS AND METHODS}

\section{Simulations}

The Molly cow model described by Baldwin (1995) with modifications (Hanigan et al., 2006, 2009) includ- 
ing recently derived digestion parameters (Hanigan et al., 2013) was used. Simulations were conducted with acslX (V3.0; Aegis Technologies Group Inc., Huntsville, $\mathrm{AL})$. The model was run for $14 \mathrm{~d}$ for each simulation to ensure that steady state was achieved, and predictions in the last day of the simulation were used for comparison to published observations. The evaluations were conducted with ruminal water balance predictions enabled. These equations should better predict the change in water volume that occurs on different diet types and thus provide better estimates of concentrations of VFA. Ruminal VFA stoichiometric coefficients of Murphy et al. (1982) as defined by Argyle and Baldwin (1988) in Molly were set initially for a "mixed" diet regardless of diet composition, and subsequently to "concentrate" when the diet contained less than $20 \%$ forage, "forage" when it contained more than $80 \%$ forage, and to "mixed" for the remainder to test whether considering diet type had a significant effect on prediction accuracy as originally observed.

\section{Evaluation Data}

Observations of VFA production rates and concentrations collected from dairy and growing cattle were assembled from the literature (Esdale et al., 1968; Rogers and Davis, 1982; Sharp et al., 1982; Armentano and Young, 1983; Seal and Parker, 1994; Sutton et al., 2003; Markantonatos et al., 2008; Markantonatos et al., 2009). Only publications using isotope dilution techniques and reporting enough dietary information to generate inputs for the model were used (Table 1). Esdale et al. (1968) measured VFA production on corn silage and alfalfa hay diets. Rogers and Davis (1982) fed high-grain and high-roughage diets to Holstein steers that were intraruminally infused with salts. Sharp et al. (1982) fed ground and whole-grain diets to steers. Armentano and Young (1983) and Markantonatos et al. (2009) examined the effect of monensin on VFA production, whereas Seal and Parker (1994) studied the effects of 3 different levels of propionate infusion. Sutton et al. (2003) and Markantonatos et al. (2008) fed high-concentrate and low-concentrate diets. The studies varied in terms of location of rumen sampling. Sutton et al. (2003) and Sharp et al. (1982) sampled rumen contents from the ventral rumen, Seal and Parker (1994) provided no information regarding the location of sampling, and the remaining studies sampled from multiple locations and pooled to get a representative sample. Location of rumen sampling affects the $\mathrm{pH}$ and VFA concentration along with other parameters, such as ammonia and sodium concentration (Shen et al., 2012). Residual errors for $\mathrm{pH}$ and VFA concentrations and production rates were analyzed to assess the effects of sampling location using the PROC MIXED of SAS (SAS Institute Inc., Cary, NC). Because diet type (forage, concentrate, or mixed) is also clearly related to these variables and may be an underlying cause for residual errors, it was also included in the model. Residual errors were associated with diet type $(P<0.01)$ but were not associated with sampling location $(P=$ 0.29 ), suggesting that the effects of location were not large and thus inclusion of studies with divergent sampling location did not significantly bias results. Because all combinations of sampling location and diet type were not present in the data set, it was not possible to test the effect of their interaction.

Reported DMI and BW were used as model inputs. Missing nutrient values were predicted from the NRC (2001) feed library, except starch solubility and degradation, which were predicted from Tamminga et al. (1990) or Miller and Hoover (1998), and ruminal ADF degradability, which was assumed to be similar to that of NDF and was predicted from the equation of Huhtanen et al. (2010).

Residual errors of prediction were used to calculate root mean square prediction errors (RMSPE). The RMSPE were expressed as a percentage of the observed treatment means and partitioned into mean bias, slope bias, and dispersion proportions (Bibby and Toutenburg, 1977).

\section{Assessing Potential for Model Improvement}

To test the potential of applying thermodynamic regulation of VFA production within the Molly cow model, the following equations of Ungerfeld and Kohn (2006) were used to describe interconversions between acetate and propionate and tested with 2 studies (Seal and Parker, 1994; Sutton et al., 2003), which contained treatments that affected the thermodynamic balance within the rumen:

$$
\begin{gathered}
F_{A, P}=K_{A, P}[\text { acetate }]\left[\mathrm{CO}_{2}\right] P_{H_{2}}{ }^{3}\left([\mathrm{ADP}]\left[\mathrm{P}_{\mathrm{i}}\right]\left[\mathrm{H}^{+}\right]\right)^{n} ; \\
F_{P, A}=K_{P, A}[\text { propionate }]\left[\mathrm{H}_{2} \mathrm{O}\right]^{2}\left([\mathrm{ATP}]\left[\mathrm{H}_{2} \mathrm{O}\right]\right)^{n},
\end{gathered}
$$

where $K_{A, P} \quad\left(\mathrm{~L}^{(2+3 \mathrm{n})} \cdot \mathrm{mol}^{-(1+3 \mathrm{n})} \cdot \mathrm{atm}^{-3} \cdot \mathrm{d}^{-1}\right)$ represented the rate constant for acetate-to-propionate conversion and $K_{P, A}\left(\mathrm{~L}^{(3+2 \mathrm{n})} \cdot \mathrm{mol}^{-(1+2 \mathrm{n})} \cdot \mathrm{d}^{-1}\right)$ represented the rate constant for propionate-to-acetate conversion. Each rate constant was derived by study from the control treatment, the normal forage treatment of Sutton et al. (2003), and the saline infusion of Seal and Parker (1994) by algebraic rearrangement of the equations using the observed $\mathrm{pH}$ and VFA concentrations and assumed constant hydrogen pressure $\left(P_{\mathrm{H}_{2}} ; \mathrm{atm}\right)$ and concentra- 
Table 1. Summary of the reported data used to evaluate predictions of ruminal VFA production ${ }^{1}$

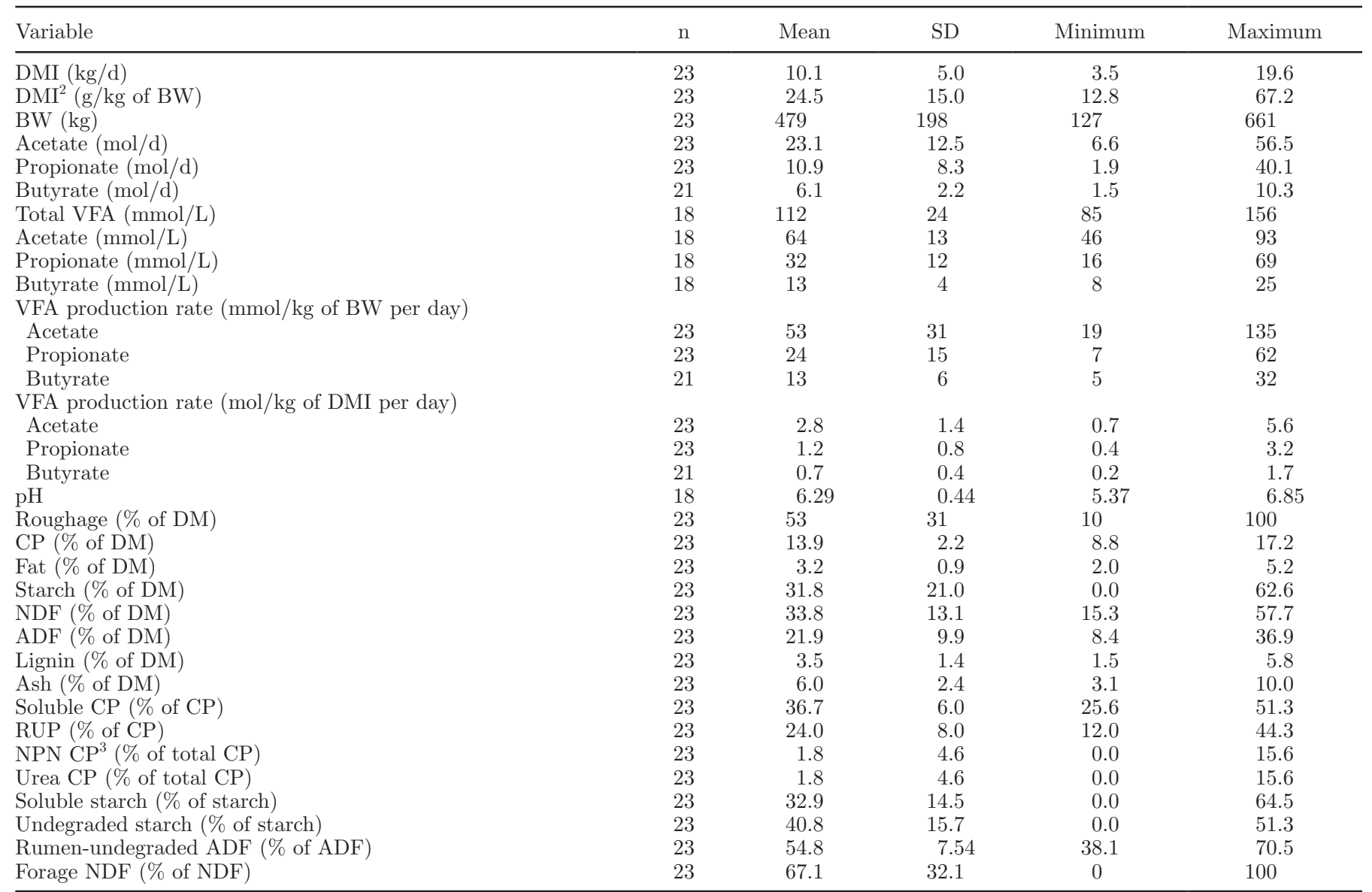

${ }^{1}$ Source data were treatment means from the experiments of Armentano and Young (1983), Esdale et al. (1968), Markantonatos et al. (2008, 2009), Rogers and Davis (1982), Seal and Parker (1994), Sharp et al. (1982), and Sutton et al. (2003).

${ }^{2}$ The DMI (g/kg of BW) for the experiment of Seal and Parker (1994) was 67.2 for 2 treatments. Animals were fed at the rate of $2.8 \mathrm{~g}$ of DM/ $\mathrm{kg}$ of BW every hour in 24 equal lots.

${ }^{3}$ Including CP from urea.

tions (mol/L) of $\mathrm{CO}_{2}, \mathrm{H}_{2} \mathrm{O}$, adenosine diphosphate (ADP), ATP, and inorganic phosphorus ( $\mathrm{P}_{\mathrm{i}}$; Ungerfeld and Kohn, 2006). The rate constants derived from the control treatment were then used with the same equation and observed $\mathrm{pH}$ and VFA concentrations from the other treatment in each study to predict fluxes between acetate and propionate $\left(F_{A, P}\right.$ and $\left.F_{P, A} ; \mathrm{mol} / \mathrm{d}\right)$. These rate constants were calculated in this manner due to the paucity of data and also because they represent the kinetic constants for the reactions, which were unknown. At equilibrium, an infinite number of forward and reverse flux combinations (kinetic rates) exist that will give a ratio of 1 ; therefore this approach allowed empirical derivation of a unique set of forward and reverse rates for the control treatment in each of the studies, which should also apply to the other treatments in that study. In theory, it should apply across studies if the concentrations of all the reactants and products were known. Thus, it is important to remember that this rate constant likely does not represent the true rate constant. The efficiency of ATP use $(n)$ was set to 0.6 , as derived by Ungerfeld and Kohn (2006).

These equations are based on the principle that the ruminal fermentation reactions are limited more by the free energy change $(\Delta \mathrm{G})$ between the substrate and product of a reaction. A reaction from A to B is thermodynamically favorable when there is a decrease in free energy going from $\mathrm{A}$ to $\mathrm{B}$ (i.e., when the $\Delta \mathrm{G}$ is negative). This reaction will be spontaneous and will release energy in the process. Similarly, zero $\Delta G$ indicates an equilibrium condition, whereas a positive $\Delta \mathrm{G}$ is thermodynamically unfavorable for proceeding forward but favorable for proceeding in the reverse direction. However, $\Delta \mathrm{G}$ does dictate the rate of the reaction, which is determined by the kinetic rate constant of the reaction. 
Table 2. Residual error analyses for predictions of ruminal VFA production and concentrations using the Murphy et al. (1982) VFA submodel within the Molly cow model (Baldwin, 1995) with modifications (Hanigan et al., 2006; 2009) ${ }^{1}$

\begin{tabular}{|c|c|c|c|c|c|c|c|}
\hline Variable & $\mathrm{n}$ & $\begin{array}{c}\text { Mean } \\
\text { observed }\end{array}$ & $\begin{array}{c}\text { Mean } \\
\text { predicted }\end{array}$ & $\begin{array}{l}\mathrm{RMSPE}^{2} \\
\text { (\% of obs) }\end{array}$ & $\begin{array}{c}\text { Mean bias } \\
\text { (\% of MSPE) }\end{array}$ & $\begin{array}{l}\text { Slope bias } \\
\text { (\% of MSPE) }\end{array}$ & $\begin{array}{c}\text { Dispersion } \\
\text { (\% of MSPE) }\end{array}$ \\
\hline Acetate synthesis $(\mathrm{mol} / \mathrm{d})$ & 23 & 23.1 & 27.2 & 63 & 8 & 33 & 59 \\
\hline Ruminal pH & 18 & 6.29 & 6.13 & 7 & 13 & 8 & 79 \\
\hline VFA $(\mathrm{mmol} / \mathrm{L})$ & 18 & 112 & 103 & 23 & 13 & 13 & 75 \\
\hline Acetate $(\mathrm{mmol} / \mathrm{L})$ & 18 & 63 & 66 & 20 & 4 & 14 & 82 \\
\hline
\end{tabular}

${ }^{1}$ Rumen liquid volume was predicted from osmotic balance. The VFA stoichiometric coefficients were set to "mixed" for all simulations. The VFA coefficients for mixed diets as defined by Argyle and Baldwin (1988) were used for all diets.

${ }^{2}$ Root mean square prediction (RMSPE) was expressed as the percentage of observed mean (obs).

The conversion of pyruvate to acetate, propionate, and butyrate all have a negative $\Delta \mathrm{G}$ and are spontaneous, and because they all share common intermediates, the interconversion between these VFA are also thermodynamically regulated (Ungerfeld and Kohn, 2006). At equilibrium, the forward and reverse flow between any 2 VFA should be equal. When a reaction is not in equilibrium, the tendency to attain equilibrium will regulate the net flow of the reaction.

\section{RESULTS AND DISCUSSION}

Using only the "mixed" diet VFA coefficients, regardless of dietary forage-to-concentrate ratios, resulted in RMSPE of 20,41, and $30 \%$ for acetate, propionate, and butyrate concentrations, respectively, with small mean bias for propionate and relatively small proportions of slope bias for acetate and butyrate (Table 2). The RMSPE for VFA production rates were 63,63 , and $49 \%$ for acetate, propionate, and butyrate, respectively. As a reference point, the standard errors of the mean from Sutton et al. (2003) were 12.2, 11.5, and $19.1 \%$ for synthesis of acetate, propionate, and butyrate respectively. Thus, the large errors of prediction did not arise solely from variance in observed data. Acetate and butyrate production rate predictions had a large proportion of the error as slope bias and propionate production had a modest proportion as mean bias. Ruminal $\mathrm{pH}$ was predicted with an RMSPE of $7 \%$, with minor mean bias and very little slope bias. Therefore, the lack of fit for VFA production data was apparently not due to problems with ruminal $\mathrm{pH}$ predictions.

Setting VFA stoichiometric coefficients by diet type did not result in improved predictions of acetate and butyrate production, with RMSPE of 64 and $49 \%$, respectively, and only a minor reduction in error for propionate (58\% RMSPE). No major changes existed in the proportioning of error among mean bias, slope bias, and dispersion (Table 3).
The slope bias for production of acetate (Figure 1) and butyrate predictions (Figure 2) was pronounced, representing 35 and $56 \%$ of the overall prediction error, respectively (Table 3 ), whereas little evidence of slope bias was present in propionate predictions (Figure 3). The negative slope for acetate production residuals is consistent with a slope less than 1 for regressions of production rate on concentration observed by Nozière et al. (2011), given that the Murphy et al. (1982) coefficients were derived using concentration data. But negative slope bias for butyrate is not consistent with a slope greater than 1 for the production and concentration regression of Nozière et al. (2011). The lack of concordance between production and concentration for acetate and butyrate indicates that production, absorption, or passage from the rumen are being influenced by factors associated with the respective VFA concentrations, any of which undermine the Murphy et al. (1982) assumption that concentration and production are absolutely proportional. Obviously, this would have biased the original stoichiometric derivations. However, if that were the only problem, bias in the production predictions and not in the concentration predictions would be expected.

Predictions of acetate and butyrate concentrations also had negative slope bias, whereas no slope bias existed for propionate concentration predictions (Table 2 ). The presence of negative slope bias for acetate and butyrate concentrations and the lack of such bias for propionate seem to rule out problems with passage, assuming all 3 VFA are passing by bulk liquid flow. These observations and those of Morvay et al. (2011) clearly indicate that the representation of VFA production is more complex and cannot be achieved with a simple set or even multiple sets of coefficients. If improvements in prediction accuracy are to be achieved, a different and more holistic approach is needed.

A potential contributing factor to the above prediction errors is the assumption that the net yield of 


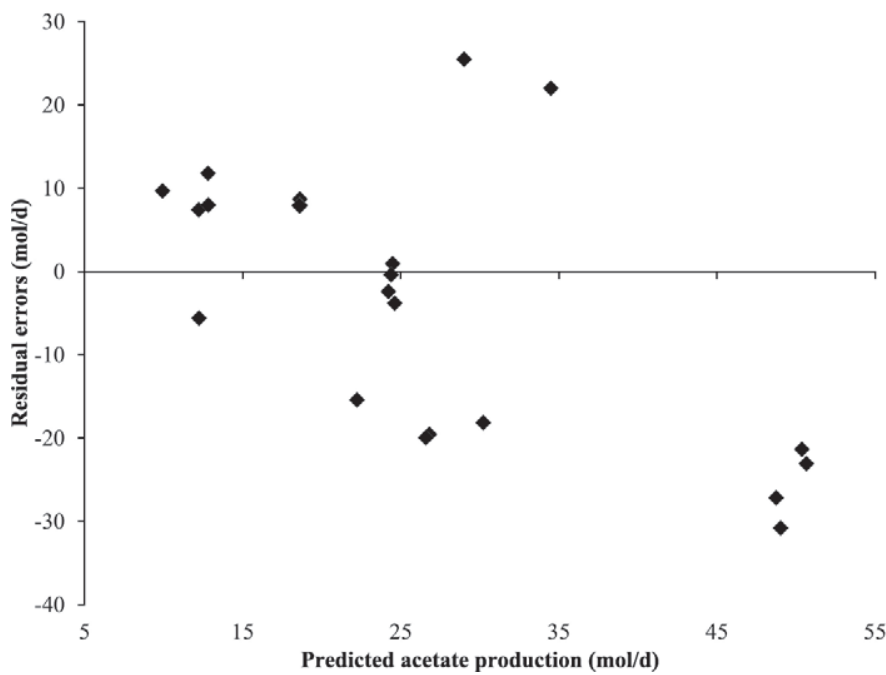

Figure 1. Residual errors versus predicted ruminal acetate production using the model of Murphy et al. (1982) as represented in the Molly cow model (Baldwin, 1995) with modifications (Hanigan et al., 2006, 2009).

individual VFA from a given nutrient is fixed. Because interconversions among VFA occur and the extent is subject to the variable thermodynamic forces in the rumen, the net yield of individual VFA cannot be fixed with respect to nutrients fermented. For example, the presence of high proton $\left(\mathrm{H}^{+}\right)$concentrations in the rumen would push net yields from acetate and butyrate to propionate (Hegarty and Gerdes, 1999). When rate constants for interconversion of acetate and propionate were derived from the high-forage diet of Sutton et al. (2003), thermodynamic forces predicted the observed increase in acetate-to-propionate interconversion and propionate-to-acetate conversion for the low-roughage diet. However, the absolute changes in the latter were overpredicted (Table 4). The predicted changes in acetate to butyrate exchange were also well predicted by

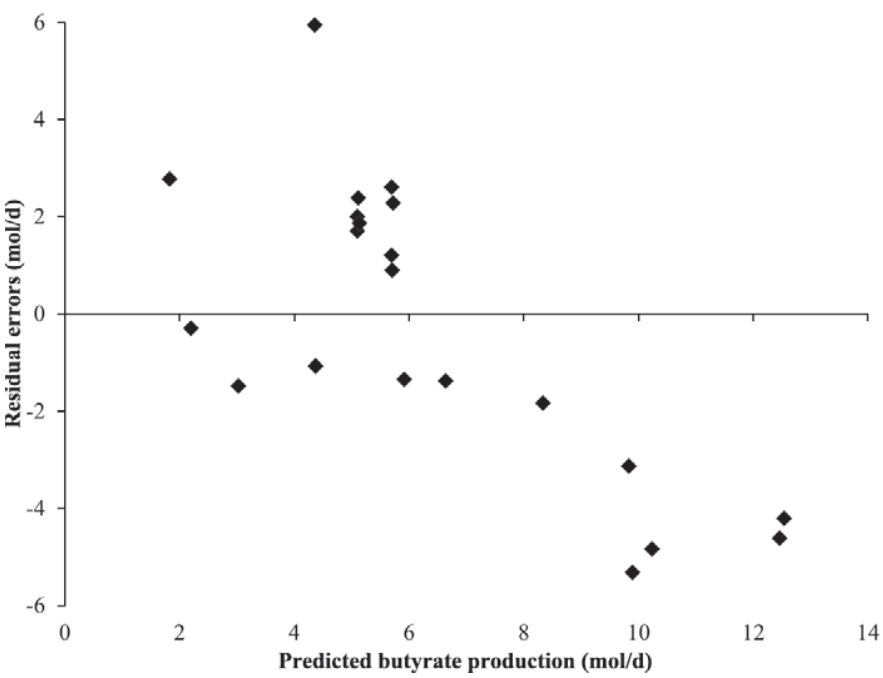

Figure 2. Residual errors versus predicted ruminal butyrate production using the model of Murphy et al. (1982) as represented in the Molly cow model (Baldwin, 1995) with modifications (Hanigan et al., 2006, 2009).

this approach (data not shown). When applied in a similar manner to the propionate infusion data of Seal and Parker (1994), the change in propionate concentration elicited the observed increase in propionate-to-acetate flux, but the model failed to predict the observed reduction in acetate-to-propionate flux. In the Sutton et al. (2003) study, the low-roughage treatment was $90 \%$ concentrate compared with $60 \%$ in the control. Similarly, Seal and Parker (1994) infused $1 \mathrm{~mol} / \mathrm{d}$ of propionic acid. In both studies, thermodynamic forces would predict increased flow of propionate to acetate. The observed and predicted increase was 1.5 and 1.3 times in Sutton et al. (2003) and 3.2 and 1.8 times in Seal and Parker (1994), respectively. In the latter work, ruminal $\mathrm{pH}$ was not reported. A shift in ruminal $\mathrm{pH}$ and change in available $\mathrm{H}$ or other products associated

Table 3. Residual error analyses for predictions of ruminal VFA production and concentrations using the Murphy et al. (1982) VFA submodel within the Molly cow model (Baldwin, 1995) with modifications (Hanigan et al., 2006, 2009) ${ }^{1}$

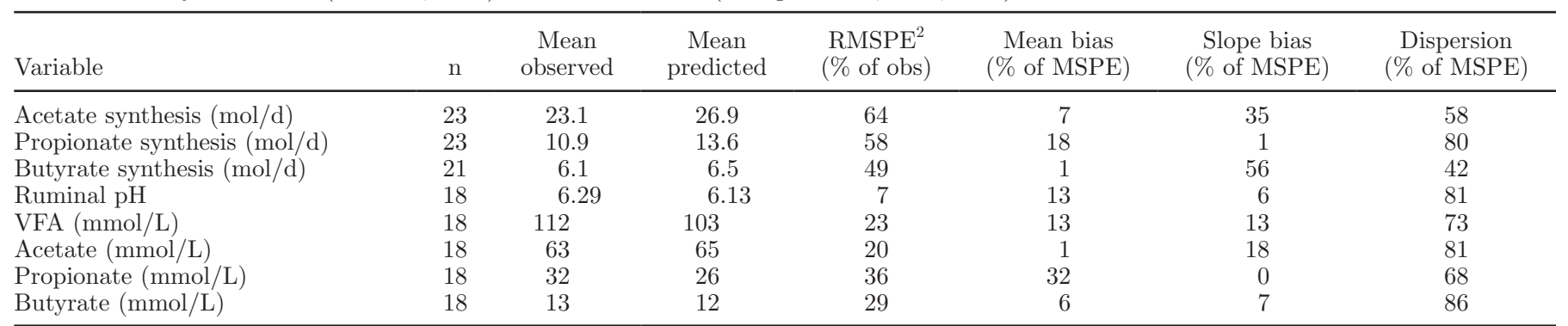

${ }^{1}$ Rumen liquid volume was predicted from osmotic balance. The VFA stoichiometric coefficients were set to "forage" for diets with $>80 \%$ forage, "concentrate" for diets with $<20 \%$ forage, and "mixed" for the remaining diets. The VFA coefficients for concentrate, mixed, and forage diets as defined by Argyle and Baldwin (1988) were used as specified.

${ }^{2}$ Root mean square prediction error (RMSPE) is expressed as the percentage of the observed mean (obs). 


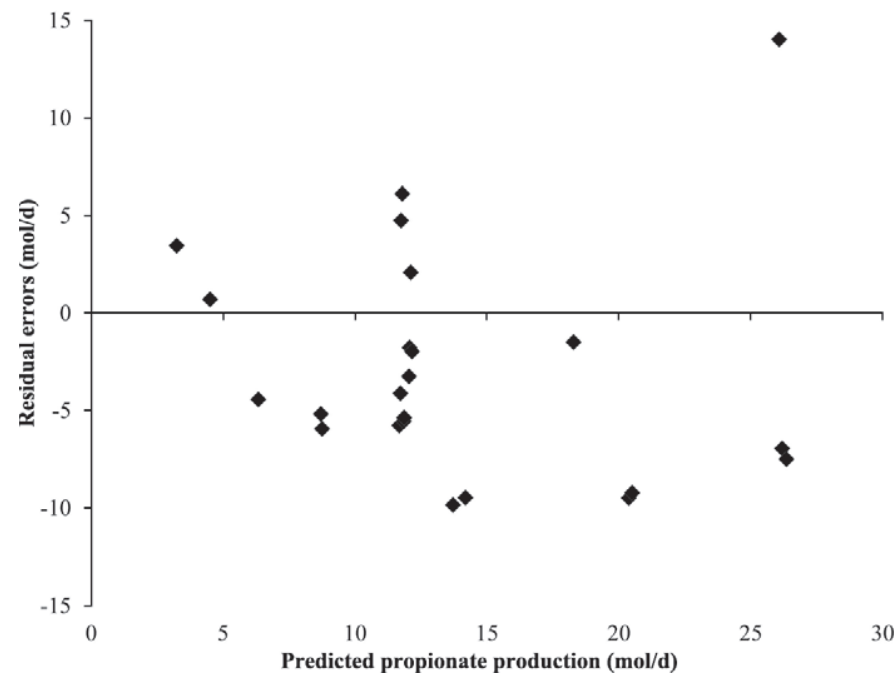

Figure 3. Residual errors versus predicted ruminal propionate production using the model of Murphy et al. (1982) as represented in the Molly cow model (Baldwin, 1995) with modifications (Hanigan et al., 2006, 2009).

with the infusion could have explained the observed reduction in acetate-to-propionate flux. In the same manner, lack of complete data or, perhaps, use of inappropriate exponents for the equations could explain the overprediction of changes in propionate-to-acetate flux for the Sutton et al. (2003) experiment. Clearly, some of the assumed reactant or product concentrations must be wrong, as the derived rate constants for the forward and reverse rates should be equal, given that the reactions occur through the same pathway.
Despite the limitations in applying thermodynamic concepts to the rumen, the fact that interconversions of VFA occur and that they appear to be thermodynamically driven undermines the approach taken by Murphy et al. (1982) to derive a set of stoichiometric coefficients for net conversion and perhaps explains some of the large prediction errors associated with predictions of VFA production for those equations. The use of VFA concentrations to derive stoichiometric coefficients also adds to the prediction error, as the relationships are not proportional across VFA (Nozière et al., 2011). However, the general approach may still have merit if the coefficients are derived for net synthesis rates, with consideration of thermodynamically driven interconversions, and if VFA absorption and passage are predicted without bias.

It is unclear how well measurements of VFA production from sheep represent those of cattle. Nozière et al. (2011) were able to accommodate sheep and buffalo data in their meta-analyses; however, they exhibit different eating and digestive patterns compared with cattle (Van Soest, 1982), which may limit their use in deriving bovine parameters. Because data used herein were restricted to those generated from cattle, the dietary variation required to develop a robust set of predictions was not possible. However, they may be adequate to anchor predictions of VFA production rates while using the much larger concentration data set to gain the required variation in dietary inputs. Because the small VFA production data set includes observations of VFA concentrations, these data can also be

Table 4. Predictions of interconversions (mol/d) between acetate (A) and propionate $(\mathrm{P})$ for 2 studies in the literature (Seal and Parker, 1994; Sutton et al., 2003) $)^{1,2}$

\begin{tabular}{|c|c|c|c|c|c|c|c|}
\hline Study & {$\left[\mathrm{H}^{+}\right](M)$} & \multicolumn{2}{|c|}{ Calculated K } & \multicolumn{2}{|c|}{ Observed flow $(\mathrm{mol} / \mathrm{d})$} & \multicolumn{2}{|c|}{ Predicted flow $(\mathrm{mol} / \mathrm{d})$} \\
\hline \multicolumn{8}{|c|}{ Sutton et al. (2003) } \\
\hline Normal & $1.7 \times 10^{-07}$ & $7.6 \times 10^{20}$ & 0.226 & 1.20 & 1.53 & 1.20 & 1.53 \\
\hline Low roughage & $3.2 \times 10^{-07}$ & & & 1.45 & 2.3 & 1.42 & 3.21 \\
\hline Change $(\%)$ & 90 & & & 21 & 50 & 18 & 109 \\
\hline $\mathrm{P}$ infusion & $3.2 \times 10^{-07}$ & & & 0.20 & 0.64 & 0.36 & 0.65 \\
\hline Change (\%) & 0 & & & -43 & 56 & 3 & 59 \\
\hline
\end{tabular}

${ }^{1}$ The rate constants were calculated from the control data and used to predict the alternative treatment in each study. All substrates were considered in each flux.

${ }^{2}$ The forward and reverse rate constants were calculated from observed flows for control treatments using the equations of Ungerfeld and Kohn (2006): $\mathrm{K}_{(\mathrm{A}->\mathrm{P})}=\mathrm{V}_{(\mathrm{A}->\mathrm{P})} /\left[\mathrm{CH}_{3} \mathrm{COO}^{-}\right]\left[\mathrm{CO}_{2}\right] \mathrm{PH}_{2}{ }^{3}\left([\mathrm{ADP}]\left[\mathrm{P}_{\mathrm{i}}\right]\left[\mathrm{H}^{+}\right]\right)^{\mathrm{n}}$ and $\mathrm{K}_{(\mathrm{P}->\mathrm{A})}=\mathrm{V}_{(\mathrm{P}->\mathrm{A})} /\left[\mathrm{CH}_{3} \mathrm{CH}_{2} \mathrm{COO}^{-}\right]\left[\mathrm{H}_{2} \mathrm{O}\right]\left([\mathrm{ATP}]\left[\mathrm{H}_{2} \mathrm{O}\right]\right)^{\mathrm{n}}$, where $\mathrm{K}_{(\mathrm{A}->\mathrm{P})}=$ rate constant for the acetate-to-propionate flux, $\mathrm{K}_{(\mathrm{P}->\mathrm{A})}=$ rate constant for the propionate-to-acetate flux, $\mathrm{V}(\mathrm{A}->\mathrm{P})=$ velocity for the acetate-to-propionate flux $(\mathrm{mol} / \mathrm{d}), \mathrm{V}_{(\mathrm{P}->\mathrm{A})}=$ velocity for the propionate-to-acetate flux $(\mathrm{mol} / \mathrm{d}), \mathrm{ADP}=$ adenosine diphosphate, $\mathrm{P}_{\mathrm{i}}=$ inorganic phosphorus, $[\mathrm{x}]=$ concentration $(\mathrm{mol} / \mathrm{L})$, and $\mathrm{n}=$ moles of ATP generated or consumed. Concentrations of VFA and velocities were as reported. Concentrations of $\mathrm{H}^{+}$were determined from $\mathrm{pH}$. The $\mathrm{CO}_{2}$ and $\mathrm{H}_{2}$ concentrations were determined as previously described (Kohn and Boston, 2000). Concentrations of ADP, ATP, $\mathrm{P}_{\mathrm{i}}$, and water were as previously reported (Ungerfeld and Kohn, 2006).

${ }^{3}$ The $\mathrm{H}^{+}$concentrations were assumed for the Seal and Parker (1994) experiment. 
used to correct any problems with VFA absorption predictions in the model. A proven absorption model overcomes the limitation associated with assuming that concentrations are proportional to production (Murphy et al., 1982). With confidence in absorption predictions, it then becomes possible to derive power from the extensive observations of VFA concentrations reported in the literature to derive production rates. This would result in enough dietary diversity to ensure robustness of the derived stoichiometric coefficients. If this approach is undertaken, it is critical that the coefficients are derived from a model that considers thermodynamically driven interconversions of VFA so that the new coefficients reflect de novo synthesis rates. This combination approach should generate more accurate predictions of net production, which will be responsive to diet as well as ruminal reactant and product concentrations.

From the analyses presented above, it is not possible to determine if 3 discrete sets of coefficients, as derived by Argyle and Baldwin (1988), are adequate to represent the full range of dietary conditions required to serve the cattle industry. If one assumes that 10 microbes represent the majority of the total biomass and that each has a unique VFA production profile, then as many as 10 sets of coefficients may be required. Nagorcka et al. (2000) used this approach, assuming 3 species, and achieved more accurate predictions of VFA concentrations in the Dijkstra et al. (1992) model. However, the improvement may simply reflect a better set of coefficients, as the number of coefficient sets used is the same as used by Argyle and Baldwin (1988) and, thus, no additional complexity was added to the model. The approach simply substituted 3 diet types by 3 sets of microbes.

Including a thermodynamic submodel should allow exploration and prediction of a broader range of methane-mitigation strategies than currently possible. Modifiers of rumen function that affect passage rate or absorption rate, such as buffers, salt, and feeding frequency, among others, will affect ruminal reactant and product concentrations. Some of these may result in significant changes in VFA patterns. Unique combinations of such strategies that result in significant shifts in VFA patterns may not be evident, but could be identified with such a model. The model would also allow quantitative relationships relating inputs and responses to be developed that allow rationale economic decisions to be made.

\section{CONCLUSIONS}

The Molly cow model did not perform well in predicting ruminal VFA production rates as evidenced by RMSPE of $50 \%$ or more for 3 major VFA. Variation in VFA interconversion appears to be driven, at least partially, by thermodynamic forces, which results in a significant violation of one of the assumptions used by Murphy et al. (1987) to derive the original estimates of net synthesis rates of VFA as used in the model. Although data that can be used to define thermodynamic state in the rumen are minimal, it may be possible to improve predictions by including thermodynamic equations for interconversion of VFA with just VFA and $\mathrm{H}^{+}$concentrations as driving variables and refitting VFA fermentation coefficients. If this approach proves beneficial, it will likely stimulate collection of the additional data in future experiments.

\section{ACKNOWLEDGMENTS}

The New Zealand Agricultural Greenhouse Gas Research Centre (Palmerston North, New Zealand) provided salary support for M. D. Hanigan to conduct a portion of this work.

\section{REFERENCES}

Argyle, J. L., and R. L. Baldwin. 1988. Modeling of rumen water kinetics and effects of rumen pH changes. J. Dairy Sci. 71:1178-1188.

Armentano, L. E., and J. W. Young. 1983. Production and metabolism of volatile fatty acids, glucose and $\mathrm{CO}_{2}$ in steers and the effects of monensin on volatile fatty acid kinetics. J. Nutr. 113:1265-1277.

Baldwin, R. L. 1995. Modeling Ruminant Digestion and Metabolism. Chapman and Hall, London, UK.

Bannink, A., H. De Visser, A. Klop, J. Dijkstra, and J. France. 1997. Causes of inaccurate prediction of volatile fatty acids by simulation models of rumen function in lactating cows. J. Theor. Biol. 189:353-366.

Bergman, E. N. 1990. Energy contributions of volatile fatty acids from the gastrointestinal tract in various species. Physiol. Rev. 70:567-590.

Bibby, J., and H. Toutenburg. 1977. Prediction and Improved Estimation in Linear Models. John Wiley \& Sons Inc., Chichester, UK.

Dijkstra, J., H. D. Neal, D. E. Beever, and J. France. 1992. Simulation of nutrient digestion, absorption and outflow in the rumen: Model description. J. Nutr. 122:2239-2256.

Elliot, J. M., and J. K. Loosli. 1959. Relationship of milk production efficiency to the relative proportions of the rumen volatile fatty acids. J. Dairy Sci. 42:843-848.

Esdale, W. J., G. A. Broderick, and L. D. Satter. 1968. Measurement of ruminal volatile fatty acid production from alfalfa hay or corn silage rations using a continuous infusion isotope dilution technique. J. Dairy Sci. 51:1823-1830.

France, J., and J. Dijkstra. 2005. Volatile fatty acid production. Pages 157-176 in Quantitative Aspects of Ruminant Digestion and Metabolism. 2nd ed. J. Dijkstra, J. M. Forbes, and J. France, ed. CABI Publishing, Wallingford, UK.

Hanigan, M. D., J. A. D. R. N. Appuhamy, and P. Gregorini. 2013. Revised digestive parameter estimates for the Molly cow model. J. Dairy Sci. 96:3867-3885.

Hanigan, M. D., H. G. Bateman, J. G. Fadel, J. P. McNamara, and N. E. Smith. 2006. An ingredient-based input scheme for Molly. Pages 328-348 in Nutrient Digestion and Utilization in Farm Animals: Modelling Approaches. E. Kebreab, J. Dijkstra, A. Bannink, W. Gerrits, and J. France, ed. CAB International, Wallingford, UK.

Hanigan, M. D., C. C. Palliser, and P. Gregorini. 2009. Altering the representation of hormones and adding consideration of gestational metabolism in a metabolic cow model reduced prediction errors. J. Dairy Sci. 92:5043-5056. 
Hegarty, R. S., and R. Gerdes. 1999. Hydrogen production and transfer in the rumen. Recent Adv. Anim. Nutr. Austral. 12:37-44.

Hegarty, R. S., and J. V. Nolan. 2007. Estimation of ruminal methane production from measurement of volatile fatty acid production. Pages 69-92 in Measuring Methane Production from Ruminants. H. P. S. Makkar and P. E. Vercoe, ed. Springer, Dordrecht, the Netherlands.

Huhtanen, P., S. Ahvenjärvi, G. A. Broderick, S. M. Reynal, and K. J. Shingfield. 2010. Quantifying ruminal digestion of organic matter and neutral detergent fiber using the omasal sampling technique in cattle - A meta-analysis. J. Dairy Sci. 93:3203-3215.

Janssen, P. H. 2010. Influence of hydrogen on rumen methane formation and fermentation balances through microbial growth kinetics and fermentation thermodynamics. Anim. Feed Sci. Technol. $160: 1-22$.

Kohn, R. A., and R. C. Boston. 2000. The role of thermodynamics in controlling rumen metabolism. Pages 11-24 in Modelling Nutrient Utilization in Farm Animals. J. P. McNamara, J. France, and D. E. Beever, ed. CABI Publishing, Wallingford, UK.

Koong, L. J., R. L. Baldwin, M. J. Ulyatt, and T. J. Charlesworth 1975. Iterative computation of metabolic flux and stoichiometric parameters for alternate pathways in rumen fermentation. Comput. Programs Biomed. 4:209-213.

Leng, R. A., and G. J. Leonard. 1965. Measurement of the rates of production of acetic, propionic and butyric acids in the rumen of sheep. Br. J. Nutr. 19:469-484.

Markantonatos, X., Y. Aharoni, L. F. Richardson, and G. A. Varga 2009. Effects of monensin on volatile fatty acid metabolism in periparturient dairy cows using compartmental analysis. Anim. Feed Sci. Technol. 153:11-27.

Markantonatos, X., M. H. Green, and G. A. Varga. 2008. Use of compartmental analysis to study ruminal volatile fatty acid metabolism under steady state conditions in Holstein heifers. Anim. Feed Sci. Technol. 143:70-88.

McAllister, T. A., and C. J. Newbold. 2008. Redirecting rumen fermentation to reduce methanogenesis. Aust. J. Exp. Agric. 48:7-13.

Miller, T. K., and W. H. Hoover. 1998. Nutrient analysis of feedstuffs including carbohydrates. Animal Science Report. West Virginia University, Morgantown.

Moloney, A. P. 1998. Growth and carcass composition in sheep offered isoenergetic rations which resulted in different concentrations of ruminal metabolites. Livest. Prod. Sci. 56:157-164.

Morvay, Y., A. Bannink, J. France, E. Kebreab, and J. Dijkstra. 2011. Evaluation of models to predict the stoichiometry of volatile fatty acid profiles in rumen fluid of lactating Holstein cows. J. Dairy Sci. 94:3063-3080

Murphy, M., P. Uden, D. L. Palmquist, and H. Wiktorsson. 1987. Rumen and total diet digestibilities in lactating cows fed diets containing full-fat rapeseed. J. Dairy Sci. 70:1572-1582.
Murphy, M. R., R. L. Baldwin, and L. J. Koong. 1982. Estimation of stoichiometric parameters for rumen fermentation of roughage and concentrate diets. J. Anim. Sci. 55:411-421.

Nagorcka, B. N., G. L. R. Gordon, and R. A. Dynes. 2000. Towards a more accurate representation of fermentation in mathematical models of the rumen. Pages 37-48 in Modelling Nutrient Utilization in Farm Animals. J. P. McNamara, J. France, and D. E. Beever, ed. CABI, Wallingford, UK.

Nozière, P., F. Glasser, and D. Sauvant. 2011. In vivo production and molar percentages of volatile fatty acids in the rumen: A quantitative review by an empirical approach. Animal 5:403-414.

NRC. 2001. Nutrient Requirements of Dairy Cattle. 7th rev. ed. Nat. Acad. Press, Washington, DC.

Rodríguez, J., R. Kleerebezem, J. M. Lema, and M. C. M. van Loosdrecht. 2006. Modeling product formation in anaerobic mixed culture fermentations. Biotechnol. Bioeng. 93:592-606.

Rogers, J. A., and C. L. Davis. 1982. Effects of intraruminal infusions of mineral salts on volatile fatty acid production in steers fed highgrain and high-roughage diets. J. Dairy Sci. 65:953-962.

Seal, C. J., and D. S. Parker. 1994. Effect of intraruminal propionic acid infusion on metabolism of mesenteric- and portal-drained viscera in growing steers fed a forage diet. 1. Volatile fatty acids, glucose, and lactate. J. Anim. Sci. 72:1325-1334.

Sharp, W. M., R. R. Johnson, and F. N. Owens. 1982. Ruminal VFA production with steers fed whole or ground corn grain. J. Anim. Sci. 55:1505-1514

Shen, J. S., Z. Chai, L. J. Song, J. X. Liu, and Y. M. Wu. 2012. Insertion depth of oral stomach tubes may affect the fermentation parameters of ruminal fluid collected in dairy cows. J. Dairy Sci 95:5978-5984

Sutton, J. D., M. S. Dhanoa, S. V. Morant, J. France, D. J. Napper, and E. Schuller. 2003. Rates of production of acetate, propionate, and butyrate in the rumen of lactating dairy cows given normal and low-roughage diets. J. Dairy Sci. 86:3620-3633.

Tamminga, S., A. M. van Vuuren, C. J. van der Koelen, R. S. Ketelaar, and P. L. d. van der Togt. 1990. Ruminal behaviour of structural carbohydrates, non-structural carbohydrates and crude protein from concentrate ingredients in dairy cows. Neth. J. Agric. Sci. 38:513-526.

Ungerfeld, E. M., and R. A. Kohn. 2006. The role of thermodynamics in the control of ruminal fermentation. Pages 55-86 in Ruminant Physiology: Digestion, Metabolism, and Impact of Nutrition on Gene Expression, Immunology and Stress. K. Sejrsen, T. Hvelplund, and M. O. Nielsen, ed. Wageningen Academic Publishers, Wageningen, the Netherlands.

Van Soest, P. J. 1982. Nutritional Ecology of the Ruminant. O \& B Books Inc., Corvallis, OR. 